\title{
MOLECULAR EPIDEMIOLOGY OF DENGUE 2 VIRUSES IN THE PHILIPPINES: GENOTYPE SHIFT AND LOCAL EVOLUTION
}

\author{
LEONORA T. D. SALDA, MARIA D. C. PARQUET, RONALD R. MATIAS, FILIPINAS F. NATIVIDAD, \\ NOBOYUKI KOBAYASHI, AND KOUICHI MORITA* \\ Department of Molecular Microbiology and Immunology, Graduate School of Biomedical Sciences, Nagasaki University, Nagasaki \\ City, Japan; Department of Virology, Institute of Tropical Medicine, Nagasaki University, Nagasaki City, Japan; Research and \\ Biotechnology Division, St. Luke's Medical Center, Quezon City, Philippines
}

\begin{abstract}
The pre-membrane (prM) and envelope (E) genes of 41 viruses isolated from dengue fever (DF), dengue hemorrhagic fever (DHF), and dengue shock syndrome (DSS) patients from 1995 to 2002 were sequenced to determine the genetic variability of dengue 2 (DENV 2) viruses in the Philippines. The envelope sequence data were compared with a global sample of DENV 2 obtained from GenBank. Phylogenetic analysis revealed that two distinct genotypes, Asian 2 and Cosmopolitan, are currently circulating locally, each with the potential to cause severe hemorrhagic disease. After the initial isolation in 1998, the Cosmopolitan genotype has gradually and effectively replaced Asian genotype 2 in the Philippines. Members of this genotype were closely related to viruses from Australia, Singapore, and Thailand.
\end{abstract}

\section{INTRODUCTION}

Dengue fever is one of the most important arboviral diseases in the tropical and subtropical regions with an estimated 50 million cases of dengue infection occurring annually in more than 100 countries. ${ }^{1}$ It is caused by four antigenically distinct single-strand, positive-polarity RNA viruses, denoted dengue types $1-4$ of the genus Flavivirus (family Flaviviridae). Infection with any of the dengue viruses can be manifested in a range of symptoms from relatively mild flu-like syndrome with rash (dengue fever, DF) to severe and potentially fatal disease characterized by capillary leakage, thrombocytopenia, and sometimes hypovolemic shock (dengue hemorrhagic fever, DHF/dengue shock syndrome, DSS). Host and virus specified factors that underlie the pathogenesis of DHF/DSS remain uncertain due in part to a lack of satisfactory in vivo and in vitro models. Immune enhancement mechanisms following a second heterologous dengue virus infection has been associated with a higher risk of developing DHF/DSS by a process known as antibodydependent enhancement. ${ }^{2-4}$ However, cases of DHF/DSS in confirmed primary infections have been observed. ${ }^{5,6}$ In addition, some strains have been associated with increased pathogenic potential. ${ }^{7,8}$ Previous studies have shown that changes in the viral genetic structure can contribute to shifts in the epidemic potential or pathogenicity of dengue virus serotypes. ${ }^{9-11}$ These observations point to the importance of viral factors in determining disease severity.

Comparative gene sequence analysis has demonstrated substantial genetic variation within all four dengue serotypes. ${ }^{12-17}$ To date, dengue 2 viruses (DENV 2) fall into six genotypes, including two genotypes confined to the Asian population (Asian 1 and Asian 2) and a Cosmopolitan genotype distributed in very different geographic localities. ${ }^{17}$ Whether this difference in geographic distribution translates to some genotypes having increased viral transmission potential is not clear at the moment.

Dengue fever is endemic on many islands of the Philippines with all four DENV serotypes found to be cocirculating. Mul-

* Address correspondence to Kouichi Morita, Department of Virology, Institute of Tropical Medicine, Nagasaki University, 1-12-4 Sakamoto, Nagasaki 852-8523. Japan. E-mail: moritak@net .nagasaki-u.ac.jp. tiple serotypes are transmitted during dengue outbreaks and usually more than one serotype predominates in the same outbreak. ${ }^{18,19}$ The first recognized outbreak of DHF was reported in $1954 .^{20}$ Since then, DHF has been occurring in epidemic proportions, mainly in Metro Manila and other urban and semiurban areas of the country. Major epidemics of DF/ DHF were reported in 1954, 1966, 1983, 1998, and 2001. The dengue epidemic of 1998 recorded the highest occurrence of dengue in the country's history with an overall case fatality rate of $2 \% .{ }^{21}$ DENV 2 has been the most frequently isolated serotype in this epidemic and in outbreaks/epidemics from 1995 to $2001 .^{22}$ This study aims to determine DENV 2 genetic variants circulating locally using isolates collected from 1995 to 2002 and to identify possible associations with severity of clinical presentation.

\section{MATERIALS AND METHODS}

Virus strains. The DENV 2 strains used in this study were obtained from the dengue virus collection of the Research and Biotechnology Division, St. Luke's Medical Center, Quezon City, Philippines. Samples consisted of 41 DENV 2 isolates from outbreaks and epidemics, which occurred between 1995 and 2002. Table 1 shows the year, origin, and clinical status of the isolates included in the study. All strains were determined as DENV 2 serotype by reverse transcription polymerase chain reaction (RT-PCR) using Ready-To-Go RT-PCR beads (Amersham Pharmacia Biotech, Piscataway, NJ) and DEN type specific primers. ${ }^{23}$ Virus stocks were prepared by single passage in C6/36 Aedes albopictus cell monolayers in Eagle's minimal essential medium (E-MEM) supplemented with $2 \%$ fetal calf serum (FCS) and $0.2 \mathrm{mM}$ of nonessential amino acids. Cells were incubated at $28^{\circ} \mathrm{C}$ for 5 to 7 days and observed for cytopathic effects. Infection was monitored by antigen capture ELISA as previously described, and virus-infected supernatants were harvested when antigen titer was higher than $400 \mathrm{IU} / \mathrm{mL}^{24}$ Infected culture fluid was clarified by centrifugation and virus stocks stored as individual 1-mL aliquots at $-80^{\circ} \mathrm{C}$ until use.

Preparation of viral RNA, amplification, and sequencing. Viral RNA was extracted from infected cell culture supernatant using QIAamp Viral RNA Mini kit (Qiagen, Hilden, Germany) following the manufacturer's instructions. Reverse transcription (RT) was performed using $5 \mu \mathrm{g}$ of RNA in a 
TABLE 1

Philippine dengue 2 isolates used in the study

\begin{tabular}{|c|c|c|c|c|c|}
\hline Isolate & $\begin{array}{l}\text { Clinical } \\
\text { status }\end{array}$ & Origin* & Year & Genotype & $\begin{array}{c}\text { GenBank } \\
\text { accession no. }\end{array}$ \\
\hline $\mathrm{OH} 5 \dagger$ & NA & Metro Manila & 1995 & Asian 2 & AF295697 \\
\hline $\mathrm{DOH} 34 \dagger$ & NA & Metro Manila & 1995 & Asian 2 & AF295698 \\
\hline $\mathrm{OH} 77 \dagger$ & NA & Metro Manila & 1995 & Asian 2 & IF295699 \\
\hline $\mathrm{OH} 78 \dagger$ & NA & Metro Manila & 1995 & Asian 2 & AF295700 \\
\hline $\mathrm{OH} 90$ & DF & Metro Manila & 1995 & Asian 2 & AY786367 \\
\hline OH 97 & DHF & Metro Manila & 1995 & Asian 2 & AY786368 \\
\hline $\mathrm{OH} 120 \dagger$ & DHF & Metro Manila & 1995 & Asian 2 & AF297004 \\
\hline $\mathrm{OH} 321 \dagger$ & DSS & Metro Manila & 1995 & & AF297005 \\
\hline $\mathrm{OH} 349 \dagger$ & NA & Metro Manila & 1995 & Asian 2 & AF297006 \\
\hline $\mathrm{MC} 14 \dagger$ & DHF & Metro Manila & 1995 & & AF297007 \\
\hline C 70 & DHF & & 1995 & & 6396 \\
\hline LMC 125 & NA & NA & 1995 & Asia & \\
\hline RL 3 & DHF & tro Manila & 1996 & & \\
\hline BRL $8 \dagger$ & NA & Metro Manila & 1996 & & 5694 \\
\hline & $\mathrm{DHF}$ & & 1996 & & AF295695 \\
\hline & NA & & 1996 & & 3370 \\
\hline & DHF & & 1996 & & \\
\hline I $15 \dagger$ & NA & & 194 & & \\
\hline I 27 & NA & & 1998 & & AY786371 \\
\hline & & & 19 & & \\
\hline & DHF & & 1998 & & 009 \\
\hline & DHF & va Ecija & 1999 & & 5373 \\
\hline U 3 & NA & NA & 2000 & & 36397 \\
\hline & DF & & 2000 & & AY786374 \\
\hline & & & 20 & & \\
\hline 3 & DHF & & 2001 & & \\
\hline & & & 1998 & & \\
\hline & SS & & 1998 & & 40 \\
\hline & DF & & 1999 & & 6402 \\
\hline & DF & & 1999 & & AY786401 \\
\hline & $\mathrm{DHF}$ & & 2000 & & \\
\hline & $\mathrm{HF}$ & $\mathrm{M}$ & 2000 & & \\
\hline 35 & DHF & & 2000 & & A) \\
\hline & $\mathrm{HF}$ & & 2000 & & AY786406 \\
\hline & DHF & Metro Manila & 2001 & Cosmop & AY786376 \\
\hline & & & & & \\
\hline & $\mathrm{HF}$ & & 2001 & & \\
\hline & A & & 2001 & & AY \\
\hline & DF & & 2001 & & AY786380 \\
\hline & & & 2001 & & AY786381 \\
\hline & & & & & \\
\hline & & & 2001 & & \\
\hline & DHF & Tanila & 2001 & & AY78638 \\
\hline & $\mathrm{DF}$ & & 2001 & Cosmopolitan & AY786385 \\
\hline & & Manila & 2001 & & \\
\hline & $\mathrm{DHF}$ & & 200 & & \\
\hline & & & & & \\
\hline & DF & Metro Manila & 2001 & & AY78638s \\
\hline 01St 385 & DF & Metro Manila & 2001 & Cosmopolitan & AY786390 \\
\hline & DF & & 2001 & & \\
\hline & & & 2001 & & \\
\hline & & & & & \\
\hline 01St 428 & NA & NA & 2001 & Cosmopolitan & AY786394 \\
\hline 02Sa 32 & DF & Metro Manila & 2002 & Cosmopolitan & A17005y \\
\hline
\end{tabular}

DF, dengue fever; DHF, dengue hemorrhagic fever; DSS, dengue shock syndrome; NA, not available.

* Metropolitan Manila refers to the national capital city of Manila and 16 other neighboring cities. The rest are provinces in the northern and southern parts of the Philippines.

$\dagger$ Previously sequenced Philippine isolates from GenBank.

20- $\mu \mathrm{L}$ RT reaction mixture containing $50 \mathrm{mM}$ Tris- $\mathrm{HCl}, 75$ $\mathrm{mM}$ KCl, 10 mM DTT, 10 mM dNTPs, Prime Rnase Inhibitor (Eppendorf, Hamburg, Germany), 1 unit of ReverTra Ace (Toyobo, Osaka, Japan), and 50 pmol of D2 R2591 (5'CAATCTTGTTACTGAGCGGA-3'). RT reactions were incubated at $42^{\circ} \mathrm{C}$ for 50 minutes then at $70^{\circ} \mathrm{C}$ for 15 minutes.

Amplification was performed using $5 \mu \mathrm{L}$ of cDNA in a 50 $\mu \mathrm{L}$ reaction mixture containing $10 \mathrm{mM}$ dNTPs, LA Taq DNA
Polymerase (Takara, Shiga, Japan), 10x LA PCR buffer II, 25 $\mathrm{mM} \mathrm{MgCl}_{2}$, and $50 \mathrm{pmol}$ of D2 F339 (5'-GAGAGGGTTCAGGAAAGAGA-3') and D2 R2591 primers. PCR reactions were subjected to 30 cycles of denaturation at $94^{\circ} \mathrm{C}(40$ seconds), annealing at $56^{\circ} \mathrm{C}$ (40 seconds) and extension at $72^{\circ} \mathrm{C}$ ( 2 minutes). PCR products were purified from $1.0 \%$ agarose gel using QIAEX II gel extraction kit (Qiagen, Hilden, Germany) and used as template for cycle sequencing. RT-PCR and sequencing primers were designed on the basis of published DENV sequences.

Sequencing reactions were performed as recommended in the BigDye Dideoxy Terminator sequencing kit (ABI Prism, Foster City, CA) and the products were analyzed using an automated 310 DNA sequencer (ABI Prism). Overlapping nucleic acid sequences obtained from individual sequencing reactions were combined for analysis and edited using the DNASIS program (Hitachi, Tokyo, Japan, 1995). Sequences were first aligned against a DENV 2 reference sequence, New Guinea C (GenBank number M29095). ${ }^{25}$ The fragments were then combined to obtain a continuous nucleotide sequence for each isolate resulting in a 1983bp gene sequence spanning the prM and envelope regions. All sequences generated in this study can be accessed in GenBank (refer to Table 1 for accession numbers).

Phylogenetic analysis. Because of its role in receptor binding, membrane fusion and elicitation of immune response, the E gene is the most commonly analyzed region in dengue molecular epidemiology studies. ${ }^{13,15-17,26}$ Furthermore, a large database of $\mathrm{E}$ gene sequences is available for comparative analysis.

A total of $41 \mathrm{E}$ gene sequences were generated. These were combined with $38 \mathrm{E}$ gene sequences representing viral strains from different geographic areas (Table 2) and 13 previously sequenced Philippine strains (Table 1) available in GenBank. Sequences were aligned using the multiple sequence alignment program ClustalX. ${ }^{27}$ Phylogenetic trees were constructed from the aligned nucleic acid sequence using algorithms based on distance matrix/neighbor joining (NJ) and maximum likelihood methods incorporated in the PAUP $4.0 \mathrm{~b} 10 .^{28}$ To assess the reliability of the inferred phylogenetic groupings, a bootstrap resampling was undertaken using 1,000 replicate neighbor-joining trees estimated under the ML substitution model. DENV 1 (A88, Indonesia 1988), DENV 3 (H87, Philippines 1956), and DENV 4 (814669, Dominica 1981) strains (GenBank accession numbers AB074761, M93130, AF326573, respectively) were used as outgroup to root the trees.

All 41 new local isolates and 13 previous isolates from GenBank were included in the initial phylogenetic analysis. However, isolates that showed more than $99.5 \%$ nucleotide sequence homology but were adequately represented (1995 and 2001) were removed. Hence the final tree only included representative local samples for each genotype (Asian genotype 2: 21 strains, Cosmopolitan genotype: 15 strains).

\section{RESULTS}

Nucleic acid and deduced amino acid sequences. The prM and envelope genes of 41 Philippine isolates collected from 1995 to 2002 together with DENV 2 prototype strain (New Guinea C) were aligned for comparison. Aligned sequences revealed single base substitutions scattered throughout the 
TABLE 2

Geographic origin and year of isolation of dengue 2 viruses used in the study

\begin{tabular}{|c|c|c|c|}
\hline Isolate & Country & Year & $\begin{array}{c}\text { GenBank } \\
\text { accession no. }\end{array}$ \\
\hline New Guinea C & New Guinea & 1944 & M29095 \\
\hline TR1751 & Trinidad & 1953 & L10053 \\
\hline P9-122 & India & 1957 & L10043 \\
\hline 16681 & Thailand & 1964 & M84727 \\
\hline PR159 & Puerto Rico & 1969 & L10046 \\
\hline Bangkok & Thailand & 1974 & AJ487271 \\
\hline Tonga & Tonga & 1974 & X54319 \\
\hline 1051 & Indonesia & 1976 & L10044 \\
\hline S-44552 & Seychelles & 1977 & L10047 \\
\hline D80-038 & Thailand & 1980 & M24448 \\
\hline 0190 & Burkina Faso & 1983 & L10042 \\
\hline 2088 & Philippines & 1983 & L10045 \\
\hline Jamaica/N.1409 & Jamaica & 1983 & M15075 \\
\hline D2-04 & China & 1985 & X65240 \\
\hline 1987 & Taiwan & 1987 & L10052 \\
\hline CHI43 & China & 1987 & AF204178 \\
\hline CTD113 & Vietnam & 1997 & AF410358 \\
\hline M1 & Malaysia & 1987 & X15434 \\
\hline M3 & Malaysia & 1987 & X15214 \\
\hline Ven2 & Venezuela & 1987 & AY158328 \\
\hline SL206 & Sri Lanka & 1990 & L10049 \\
\hline 40247 & Brazil & 1990 & L10041 \\
\hline CAMR2 & Singapore & 1991 & AF410368 \\
\hline CAMR8 & India & 1991 & AF10373 \\
\hline CAMR16 & Saudi Arabia & 1992 & AF410378 \\
\hline CAMR11 & Uganda & 1993 & AF410375 \\
\hline ThNH-52/93 & Thailand & 1993 & AF022436 \\
\hline TSV01 & Australia & 1993 & AY037116 \\
\hline Cook Is 1 & Australia & 1997 & AF004020 \\
\hline Torres Strait 1/1997 & Australia & 1997 & AF004019 \\
\hline $98-703$ & Martinique & 1998 & AF208496 \\
\hline CAMR13 & Far East & 1998 & AF410376 \\
\hline CAMR14 & Thailand & 1998 & AF410377 \\
\hline CTD204 & Vietnam & 1998 & AF410361 \\
\hline GD08/98 & China & 1998 & AF469176 \\
\hline 00-36-1HuNIID & Japan & 2000 & AB111451 \\
\hline 01-46-1HuNIID & Japan & 2001 & AB111454 \\
\hline GD19/2001 & China & 2001 & AF509530 \\
\hline
\end{tabular}

entire length of the prM and E genes. The majority of the substitutions occurred at the third reading frame, resulting in approximately $14.6 \%$ of the nucleotide substitutions leading to amino acid changes. There were no deletions or insertions. Nucleic acid homology among the Philippine strains ranged from $92.0 \%$ to as high as $100 \%$. Compared with DENV 2 New Guinea C strain, homology ranged from $94.6 \%$ to $95.7 \%$.

Deduced amino acid sequences among strains were highly conserved with amino acid identities ranging from 96.0$100 \%$. Most of the amino acid changes observed were conservative substitutions. None of the amino acid changes were consistent between DF and DHF/DSS samples and thus could not be correlated with disease outcome.

Phylogenetic analysis. Based on previous studies with the same E protein interval and on a short sequence in the NS1/E junction, a divergence of $6 \%$ within the studied region was taken as a cutoff point for virus groupings. ${ }^{12,16}$ Thus, five genetic subtypes, each representing a distinct genotype, could be distinguished as shown in Figure 1. Asian genotype 1 comprises viruses from Thailand, Malaysia, and China; Asian genotype 2 comprises viruses from the China, Vietnam, Philippines, Taiwan, and the dengue 2 prototype strain New Guinea $\mathrm{C}$; American/Asian genotype comprises viruses collected from Brazil, China, Thailand, Malaysia, and the Caribbean; the Cosmopolitan genotype shows a wide geographical distribution including strains from Australia, Southeast Asia, India, China, Africa, and the Middle East; and the American genotype comprises earlier Caribbean isolates from Puerto Rico, Trinidad, along with India, Tonga, and Venezuela. High bootstrap values $(70-100 \%)$ indicate robust support for the tree topology. A similar topology was obtained when phylogenies were constructed using the 240-bp E/NS1 junction (data not shown). Nucleotide sequence identity between genotypes ranged from $88.8 \%$ to $94.7 \%$.

The Philippine isolates segregated into 2 distinct groups. Asian 2 genotype was constituted mostly of earlier isolates or around $48.0 \%$ (26 of 54 ) of all local isolates obtained from 1995 to 2002 (Figure 1; Table 1). Among the Philippine Asian 2 genotype strains, two subgroups or clades can be identified with the older isolates $(1995,1996)$ clustered in one clade and relatively recent isolates $(1998,2000,2001)$ forming another clade. Both clades however appeared to share a common ancestral lineage with a 1983 isolate (Philip 2088). All Philippine Asian 2 isolates shared five conservative amino acid substitutions, lysine to glutamic acid (E126), valine to isoleucine (E129), isoleucine to valine (E322 and E378), and methionine to valine (E492), not observed in other isolates of this genotype.

Fifty-two percent (28 of 54) of all local isolates on the other hand were of Cosmopolitan genotype the majority of which were collected from 1999 to 2002 (Figure 1; Table 1). The Philippine isolates were in general, temporally clustered by year and shared an aspartic acid (D) at position E203 that is not seen in any of the strains of this genotype. These isolates clustered together with earlier isolates from Australia, Singapore, and Thailand. Nucleotide differences within this genotype ranged from $0.1 \%$ to $5.5 \%$.

\section{DISCUSSION}

Dengue outbreaks from 1995 to 2002 have consisted of a mixture of DENV serotypes. Serotypes 2 and 3 predominated from 1995 to 1998 while serotypes 2 and 1 were commonly isolated from 1999 to 2002 (Figure 2A). Of the four serotypes, DENV 2 has been consistently detected in outbreaks/ epidemics for nearly a decade (1995 to 2002). Only a limited data on the molecular epidemiology of DENV 2 in this country, however, is available. ${ }^{22,29}$ In this report, we analyzed 41 local DENV 2 isolates collected in a span of 8 years to further understand the ecology of this virus in the region.

The circulation of 2 distinct genotypes among Philippine strains reflects substantial genetic diversity of DENV 2 in this population. The Asian 2 genotype also known as Genotype II was observed in all 1995 and 1996 isolates collected from Metro Manila and from provinces to the north and south of the metropolis. A 1983 isolate (Philip 2088) also fell within this genotype. This probably represents the circulating genotype during those years. Furthermore, previous studies using the 240-bp E/NS1 junction of DENV 2 show that a 1988 isolate and 1995 isolates collected from Southern Philippines (Mindanao) fall within Asian 2 genotype. ${ }^{12,29}$ Recent years however, saw a shift in the prevalent genotype from Asian 2 to Cosmopolitan genotype (or from Genotype II to Genotype IV). ${ }^{12}$ After its detection in 1998, which incidentally reported an increase in number of dengue cases in the Philippines, the Cosmopolitan genotype gradually became dominant compris- 


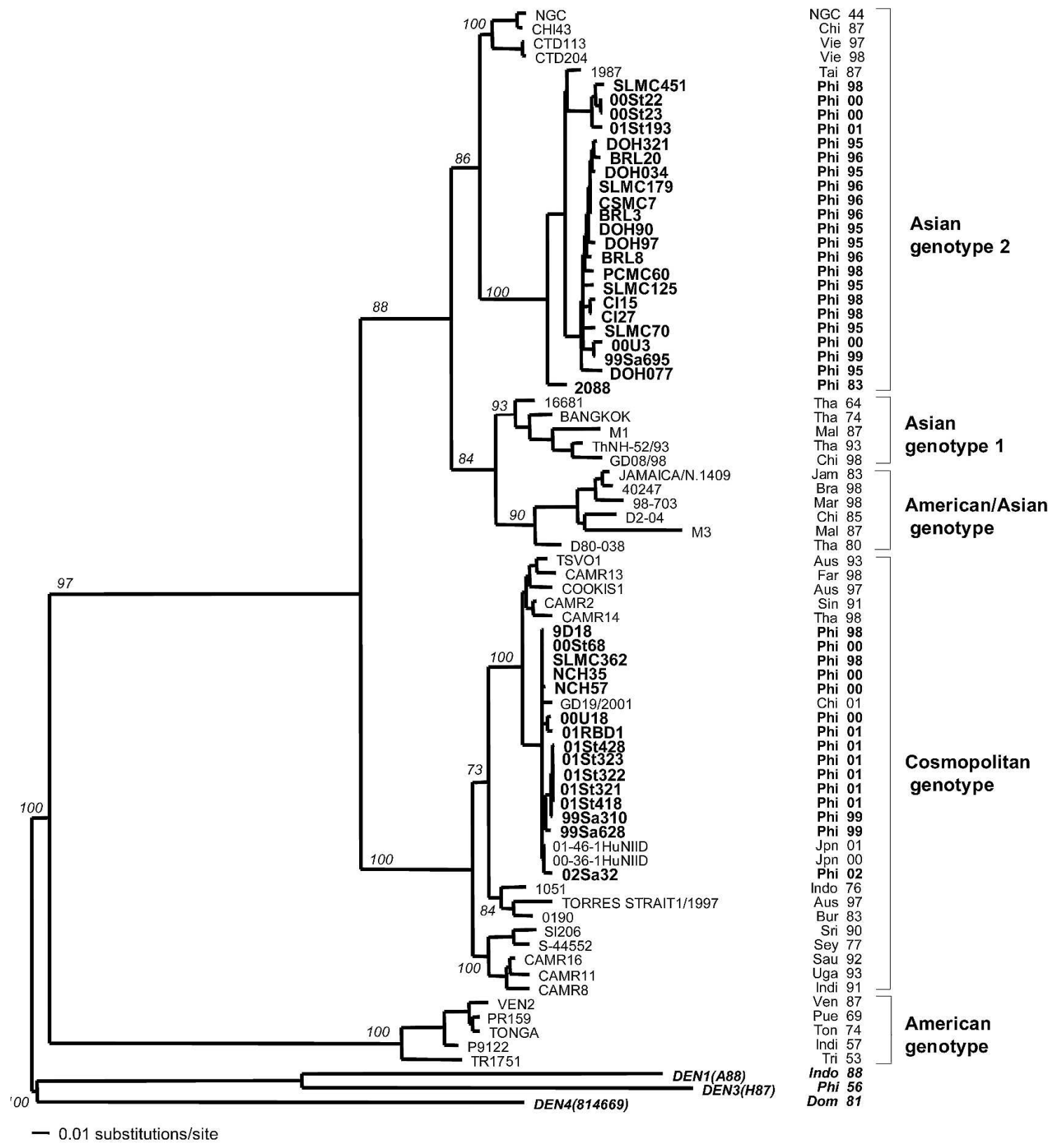

FIGURE 1. Maximum likelihood tree depicting the phylogenetic relationships of 74 dengue serotype 2 viruses based on the envelope gene (1,485 bases). Numbers on branches represent bootstrap support for each branch. Viruses are listed by strain name, country of origin, and the last 2 digits of the year of isolation. Genotypes are also indicated. Dengue serotypes 1, 3, and 4 served as outgroup. All horizontal branch lengths are drawn to scale. The countries included are NGC, New Guinea; Chi, China; Vie, Vietnam; Tai, Taiwan; Phi, Philippines; Tha, Thailand; Mal, Malaysia; Jam, Jamaica; Bra, Brazil; Mar, Martinique; Aus, Australia; Far, Far East; Sin, Singapore; Jpn, Japan; Indo, Indonesia; Bur, Burkina Faso; Sri, Sri Lanka; Sey, Seychelles; Sau, Saudi Arabia; Uga, Uganda; Indi, India; Ven, Venezuela; Pue, Puerto Rico; Tri, Trinidad; Dom, Dominica.

ing the majority of isolates from 1999 to 2002 (Figure 2B). The genotype shift was particularly evident in Metro Manila where recent samples analyzed were mostly of the Cosmopolitan genotype (Table 2). This shift was also observed in the provinces of Bulacan and Rizal, which is not surprising given the close proximity of these localities to Metro Manila. Likewise, the Cosmopolitan genotype has spread to the provinces of Pampanga and Cavite (to the north and south of Metro Manila, respectively). Further supporting its prevalence, this genotype was detected in two strains isolated from Japanese (Figure 1) dengue fever patients who apparently contracted the disease from an island 365 miles south of Manila in 2000 and 2001. ${ }^{30}$ These observations indicate displacement of Asian 2 genotype by Cosmopolitan genotype and rapid spread of the latter in Metro Manila and several provinces of the country.

Our phylogenetic analyses show that the local Cosmopolitan genotype isolates are closely related to older isolates from Singapore, Australia, and Thailand suggesting a recent introduction event at some point. These strains are distinguished from other Cosmopolitan genotype strains by an amino acid substitution (E52 Q to $\mathrm{H}$ ) and 11 silent mutations (data not 


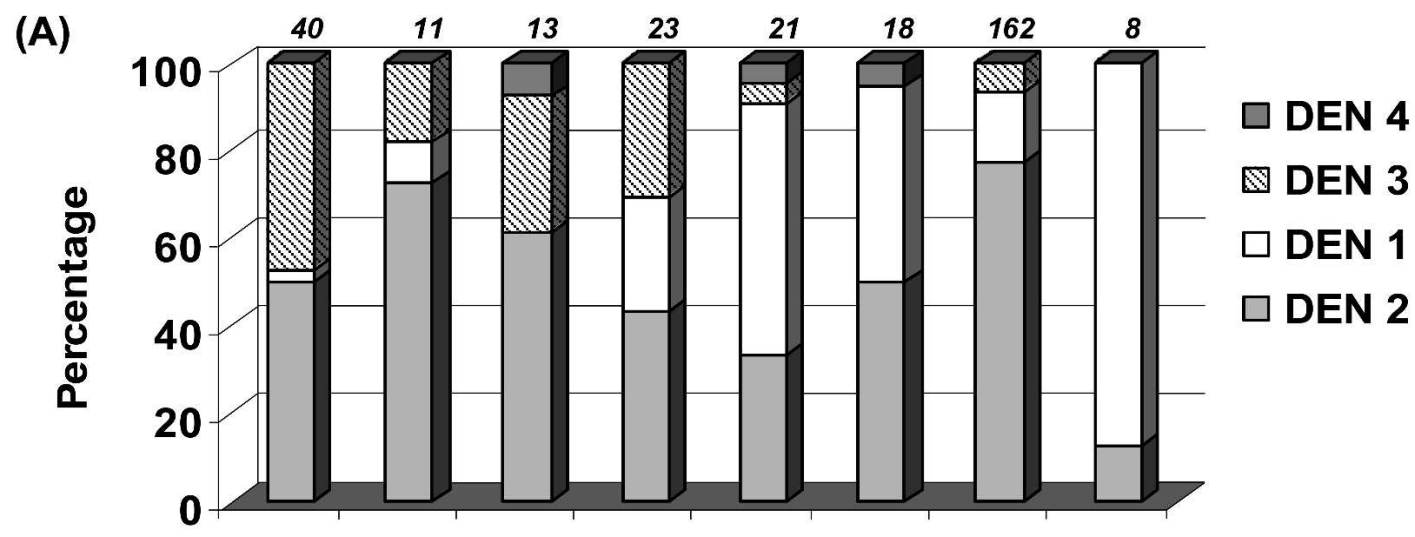

(B)

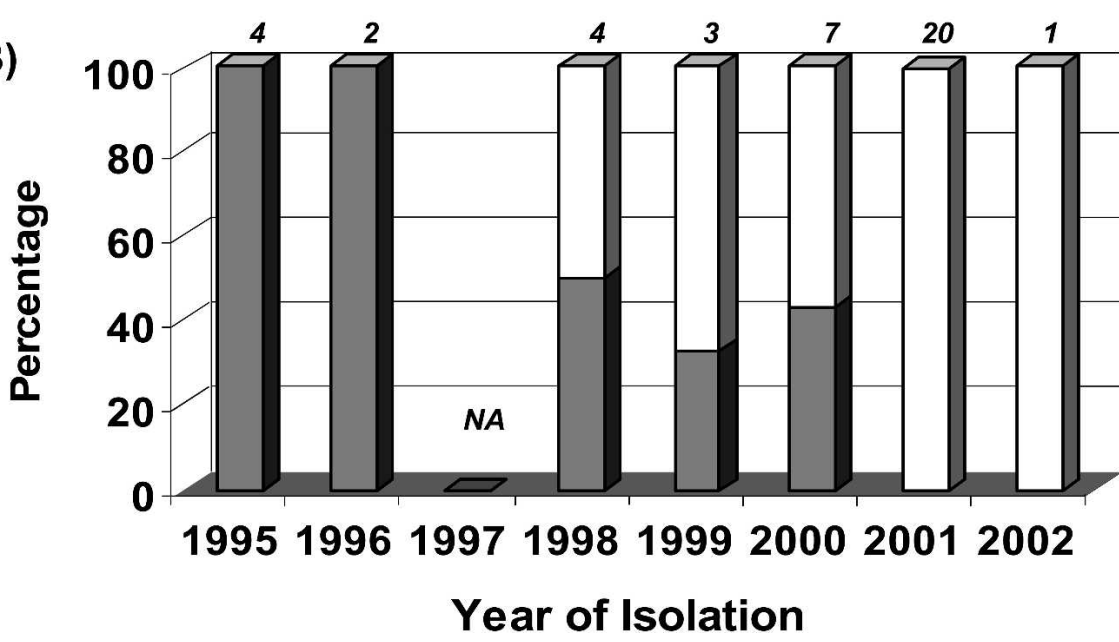

$\square$ Asian 2

$\square$ Cosmopolitan

Figure 2. A, Serotype distribution of dengue viruses in the Philippines from 1995 to 2002. B, Prevalence of Asian 2 and Cosmopolitan genotypes in the Philippines from 1995 to 2002. Percentages were calculated from a total of 41 DENV 2 strains examined. Numbers in italics specify the total number of strains analyzed for each year. NA indicates no strains analyzed.

shown) over the gene region examined. Viral traffic between countries within this region may have been promoted by geographic proximity as well as socioeconomic relations. Previous studies have documented similar observations in other regions. ${ }^{12,13,31-35}$ Initially detected in Metro Manila, the Cosmopolitan genotype could have been introduced in this area, considered the major port of entry of the country. It is likely that this genotype might have spread throughout the country within the last three years as a consequence of local social and economic activities. Analysis of more recently acquired samples from a larger number of sub-localities within the country is necessary to prove our hypothesis.

The reasons behind the rapid spread and prevalence of the Cosmopolitan genotype are yet to be defined. This genotype, observed in a diverse range of geographical areas, has been shown to replace existing strains in other countries. ${ }^{13,33}$ Positive selection acting on the E gene could account for differences in dispersal ability among DENV 2 genotypes. ${ }^{17}$ It is also possible that adaptation to mosquito vectors may have contributed to the rapid dispersal of this genotype. Dengue virus serotypes have been demonstrated to vary in their ability to infect and disseminate in mosquitoes. ${ }^{36,37}$ More specifically, DENV 2 strains of the Southeast Asian genotype have been shown to infect Aedes aegypti mosquitoes more efficiently compared with the American genotype strains. ${ }^{38}$
Some dengue virus strains may also infect and replicate more effectively in target cells. ${ }^{39,40}$ However, our initial experiments with representative isolates from Asian 2 and Cosmopolitan genotypes did not show any consistent difference in viral replication efficiency in C6/36, LLC-MK2, K562 cell lines or human dendritic cells (data not shown). Alternatively rapid spread of the Cosmopolitan genotype may, to some extent, reflect the absence of a previous exposure to this genotype in the local population. This may have resulted to a population more susceptible to the new genotype. Whatever the mechanism involved the reasons behind the rapid displacement of Asian 2 genotype by the recently introduced Cosmopolitan genotype merits further investigation.

In addition to long distance introduction, phylogenetic analysis also supports local independent evolution of DENV 2. In both genotypes, Philippine isolates formed independent clusters and were defined by amino acid changes not observed in other isolates of the same genotype.

Previous studies have identified mutations in the virus genome that are associated with changes in virulence. ${ }^{10,11}$ Among the local strains examined however, no consistent genetic differences between strains causing severe and mild disease were observed. However, the possibility of increased pathogenicity caused by nucleotide changes in the viral genome other than the prM and envelope regions cannot be 
dismissed altogether. In addition, segregation according to disease severity (DF versus DHF/DSS) was not observed suggesting that local isolates of both genotypes are likely to cause severe disease.

In summary, the phylogenetic data presented here suggests that DENV 2 strains circulating in the Philippines are primarily of the Cosmopolitan genotype, displacing Asian 2 genotype over a short period of time since its introduction in 1998. Continuous monitoring of DENV genotypes is necessary to confirm the current findings and to detect possible genotype shifts within the dengue viruses in the future.

\section{Received March 23, 2005. Accepted for publication June 1, 2005.}

Acknowledgments: The first author is a recipient of the Monbusho Scholarship from the Ministry of Education, Science Sport and Culture of Japan.

Financial support: This study was supported in part by Grant-in-Aid for scientific research (B) (no. 13576016 and no. 15406020) from the Ministry of Education, Science Sport and Culture of Japan, a Grant for Research on Emerging and Re-emerging Infections Diseases (H15-Shinko-19) from the Ministry of Health and Welfare and Labor of Japan, and the $21^{\text {st }}$ century Centers of Excellence (COE) program on "Global strategies for Control of tropical and emerging infectious diseases" Nagasaki University.

Authors' addresses: Leonora T. D. Salda, Laboratory of Molecular Pharmacology of Infectious Agents, Department of Molecular Microbiology and Immunology, Graduate School of Biomedical Sciences, Nagasaki University, 1-14 Bunkyo-machi, Nagasaki City, 8528521, Japan, Telephone: (+81) 95-819-2458, Fax: (+81) 95-849-7830, E-mail: lensalda@mxc.cncm.ne.jp. Maria D. C. Parquet, Department of Virology, Institute of Tropical Medicine, Nagasaki University, 1-12-4 Sakamoto, Nagasaki City, 852-8523, Japan, Telephone: $(+81)$ 95-849-7829, Fax: (+81) 95-849-7830, E-mail: parquet@tm.nagasakiu.ac.jp. Ronald R. Matias, Research and Biotechnology Division, St. Luke's Medical Center, 279 E. Rodriguez Sr. Blvd., Quezon City, 1102 Philippines, Telephone: (+63) 2-723-5540, Fax: (+63) 2-726-0467, E-mail: rrmatias@stluke.com.ph. Filipinas F. Natividad, Research and Biotechnology Division, St. Luke's Medical Center, 279 E. Rodriguez Sr. Blvd., Quezon City, 1102 Philippines, Telephone: $(+63)$ 2-723-5540, Fax: (+63) 2-726-0467, E-mail: ffnatividad@stlike.com.ph. Noboyuki Kobayashi, Laboratory of Molecular Pharmacology of Infectious Agents, Department of Molecular Microbiology and Immunology, Graduate School of Biomedical Sciences, Nagasaki University, 1-14 Bunkyo-machi, Nagasaki City, 852-8521, Japan, Telephone: (+81) 95-819-2458, Fax: (+81) 95-844-3783, E-mail: nobnob@ net.nagasaki-u.ac.jp. Kouichi Morita, Department of Virology, Institute of Tropical Medicine, Nagasaki University, 1-12-4 Sakamoto, Nagasaki City, 852-8523, Japan, Telephone: (+81) 95-849-7829, Fax: (+81) 95-849-7830, E-mail: moritak@net.nagasaki-u.ac.jp.

Reprint requests: Kouichi Morita, Department of Virology, Institute of Tropical Medicine, Nagasaki University, 1-12-4 Sakamoto, Nagasaki City, 852-8523, Japan, Telephone: (+81) 95-849-7829, Fax: (+81) 95-849-7830, E-mail: Moritak@net.nagasaki-u.ac.jp.

\section{REFERENCES}

1. World Health Organization, 2002. Dengue and dengue hemorrhagic fever. Fact sheet no. 117. Available at: http:// www.who.int/mediacentre/factsheets/fs117/en/print.html

2. Halstead SB, 1988. Pathogenesis of dengue: challenges to molecular biology. Science 239: 476-481.

3. Kliks SC, Nisalak A, Brandt WE, Wahl L, Burke DS, 1989. Antibody-dependent enhancement of dengue virus growth in human monocytes as a risk factor for dengue hemorrhagic fever. Am J Trop Med Hyg 40: 444-451.

4. Thein S, Aung MM, Shwe TN, Aye M, Zaw A, Aye K, Aye KM, Aaskov J, 1997. Risk factors in dengue shock syndrome. Am J Trop Med Hyg 56: 566-572.

5. Barnes WJ, Rosen L, 1974. Fatal hemorrhagic disease and shock associated with primary dengue infection on a Pacific island. Am J Trop Med Hyg 23: 495-506.

6. Scott RM, Nimmannitya S, Bancroft WH, Mansuwan P, 1976. Shock syndrome in primary dengue infections. Am J Trop Med Hyg 25: 866-874.

7. Chungue E, Deubel V, Cassar O, Laille M, Martin PMV, 1993. Molecular epidemiology of dengue 3 viruses and genetic relatedness among dengue 3 strains isolated from patients with mild or severe form of dengue fever in French Polynesia. J Gen Virol 74: 2765-2770.

8. Rico-Hesse R, Harrison LM, Salas RA, Tovar D, Nisalak A, Ramos C, Boshell J, Meas MT, Nogueira RH, Rosa AT, 1997. Origins of dengue type 2 viruses associated with increased pathogenecity in the Americas. Virology 230: 244-251.

9. Gubler DG, Suharyano W, Lubis I, Eram S, Gunarso S, 1981. Epidemic dengue 3 in Central Java, associated with low viremia in man. Am J Trop Med Hyg 30: 1094-1099.

10. Leitmeyer KC, Vaughn DW, Watts DM, Salas R, Villalobos de Chacon I, Ramos C, Rico-Hesse R, 1999. Dengue virus structural differences that correlate with pathogenesis. $J$ Virol 73 : 4738-4747.

11. Pandey BD, Igarashi A, 2000. Severity-related molecular differences among nineteen strains of dengue type 2 viruses. Microbiol Immunol 44: 179-188.

12. Rico-Hesse R, 1990. Molecular evolution and distribution of dengue viruses type 1 and 2 in nature. Virology 174: 479-493.

13. Lewis JA, Chang G, Lanciotti RS, Kinney RM, Mayer LW, Trent DW, 1993. Phylogenetic relationships of dengue 2 viruses. $V i$ rology 197: 216-224.

14. Lanciotti RS, Lewis JG, Gubler DJ, Trent DW, 1994. Molecular evolution and epidemiology of dengue-3 viruses. J Gen Virol 75: 65-75.

15. Chungue E, Cassar O, Drouet MT, Guzman MG, Laile M, Rosen L, Deubel V, 1995. Molecular epidemiology of dengue-1 and dengue-4 viruses. J Gen Virol 76: 1877-1884.

16. Lanciotti RS, Gubler DJ, Trent DW, 1997. Molecular evolution and phylogeny of dengue 4 viruses. J Gen Virol 78: 2279-2286.

17. Twiddy SS, Farrar JJ, Nguyen VC, Wills B, Gould EA, Gritsun T, Lloyd G, Holmes EC, 2002. Phylogenetic relationships and differential selection pressures among genotypes of dengue 2 virus. Virology 298: 63-72.

18. Venzon EL, Rudnick A, Marchette NJ, Fable AE, Dukellis E, 1972. The greater Manila dengue hemorrhagic fever epidemic of 1966. J Phil Med Assoc 48: 297-313.

19. Hayes CG, Manaloto CR, Gonzales A, Ranoa CP, 1988. Dengue infections in the Philippines: clinical and virologic findings in 517 hospitalized patients. Am J Trop Med Hyg 39: 110-116.

20. Quintos FN, Lim LE, Juliano L, Reyes A, Lacson P, 1954. Hemorrhagic fever observed among children in the Philippines. Phil J Ped 3: 1-19.

21. Tayag EA, 1998. The dengue epidemic of 1998 in the Philippines. Den Bull 22. World Health Organization Regional Office for South-East Asia. Available at: http://w3.whosea.org/en/ Section10/Section332/Section520_2421.htm.

22. Matias RR, 2003. A historical review of dengue virus research in the Philippines. St. Luke's J Med 1: 3-8.

23. Morita K, Tanaka M, Igarashi A, 1991. Rapid identification of dengue virus serotypes by using polymerase chain reaction. $J$ Clin Mic 29: 2107-2110.

24. Igarashi A, Mohamed H, Yusof A, Sinniah M, Tanaka H, 1995. Production of type 2 dengue (D2) monoclonal antibody and cell culture derived D2 antigen for use in dengue IgM capture ELISA. Trop Med 37: 165-173.

25. Irie K, Mohan PM, Sasaguri Y, Putnak R, Padmanabhan R, 1989. Sequence analysis of cloned dengue virus type 2 genome (New Guinea C strain). Gene 75: 197-211.

26. Wang E, Ni H, Xu R, Barrett ADT, Watowich SJ, Gubler DJ, Weaver SC, 2000. Evolutionary relationships of endemic/ epidemic and sylvatic dengue viruses. $J$ Virol 74: 3227-3234.

27. Thompson JD, Gibson TJ, Plewniak F, Jeanmougin F, Higgins DG, 1997. The ClustalX windows interface: flexible strategies for multiple sequence alignment aided by quality analysis tools. Nucleic Acids Res 24: 4876-4882.

28. Swofford DL, 1998. PAUP* 4.0 - Phylogenetic analysis using 
parsimony (*and other methods) 4.0b8. Sinauer Associates, Sutherland, MA.

29. ter Meulen J, Grau M, Lenz O, Emmerich P, Schmidtz H, Oh F, Jaspert R, Niedrig M, 2000. Isolation and partial characterization of dengue virus type 2 and 4 strains from dengue fever and dengue haemorrhagic fever patients from Mindanao, Republic of the Philippines. Trop Med Int Health 5: 325-329.

30. Tokuda A, Sugito K, Tabeta H, Takasaki T, Yamada K, Kurane I, 2002. 3 dengue fever cases infected during a group tour to the Philippines. Kansenshogaku Zasshi 76: 953-957.

31. Dash PK, Parida MM, Saxena P, Kumar M, Rai A, Pasha ST, Jana AM, 2004. Emergence and continued circulation of dengue 2 (genotype IV) virus strains in northern India. $J$ Med Virol 74: 314-322.

32. Foster JE, Bennett SN, Vaughan H, Vorndam V, McMillan WO, Carrington CV, 2003. Molecular evolution and phylogeny of dengue type 4 virus in the Caribbean. Virol 306: 126-134.

33. Singh UB, Maitra A, Broor S, Rai A, Pasha ST, Seth P, 1999. Partial nucleotide sequencing and molecular evolution of epidemic causing Dengue 2 strains. J Inf Dis 180: 954-965.

34. Trent DW, Grant JA, Rosen L, Monath TP, 1983. Genetic variation among dengue 2 viruses of different geographic origin. Virology 128: 271-284.

35. Uzcategui NY, Camacho D, Comach G, Cuello de Uzcategui R,
Holmes EC, Gould EA, 2001. Molecular epidemiology of dengue type 2 virus in Venezuela: evidence for in situ virus evolution and recombination. J Gen Virol 82: 2945-2953.

36. Gubler DJ, Nalim S, Tan R, Saipan H, Sulianti SJ, 1979. Variation in susceptibility to oral infection with dengue viruses among geographic strains of Aedes aegypti. Am J Trop Med Hyg 45: 644-651.

37. Rosen L, Roseboom LE, Gubler DJ, Lien JC, Chaniotis BN, 1985. Comparative susceptibility of mosquito species and strains to oral and parenteral infection with dengue and Japanese encephalitis viruses. Am J Trop Med Hyg 34: 603-615.

38. Armstrong PM, Rico-Hesse R, 2003. Efficiency of dengue serotype 2 virus strains to infect and disseminate in Aedes aegypti. Am J Trop Med Hyg 68: 539-544.

39. Morens DM, Marchette NJ, Chu MC, Halstead SB, 1991. Growth of dengue type 2 virus isolates in human peripheral blood leukocytes correlates with severe and mild disease. Am J Trop Med Hyg 45: 644-651.

40. Wu SJ, Grouard-Vogel G, Mascola JR, Brachtel E, Putvana R, Louder MK, Filgueira L, Marovich MA, Wong HK, Blauvelt A, Murphy GS, Robb ML, Innes BL, Birx DL, Hayes CG, Frankel SS, 2000. Human skin Langerhans cells are targets of dengue virus infection. Nat Med 6: 816-820. 